\title{
The Future of Merger \\ What Do We Want Mergers To Do: Efficiency or Diversity?
}

\section{DANIEL W. LANG}

University of Toronto

\section{ABSTRACT}

Mergers have been a frequent phenomenon in higher education in the last quarter century. The conventional wisdom is that mergers are undertaken mainly for economic reasons, either to expand markets or to reduce costs. About four out of five college or university mergers survive. In the for-profit sector the comparable rate is closer to two out of five. From this one might conclude that the future for mergers among colleges and universities is robust. If, however, the principal purpose of mergers is economic efficiency, there logically ought to be a point beyond which the efficacy of merger will begin to decline. There is, however, another motive for merger, which is unrelated to economic efficiency. Mergers can produce greater diversity of programs and services, both among individual colleges and universities and within systems of postsecondary education. If diversification is the primary purpose of merger, the future might look different and might depend on new ways of identifying peers and partners for merger. This essay examines the expectations that are held for mergers, the realism of those expectations, and the means by which partners in mergers are identified and selected. It concludes with the suggestions that diversification may replace efficiency as the main stimulus of merger, and that, as the choice 
is made between efficiency and merger, institutions and systems of postsecondary education may try other, less permanent, forms of inter-institutional cooperation before committing to merge.

\section{RÉSUMÉ}

Depuis 25 ans, les fusions sont un phénomène fréquent dans l'enseignement supérieur. Selon les idées reçues, elles surviennent principalement pour des raisons économiques, soit pour développer le marché ou soit pour réduire les dépenses. Environ quatre fusions de collèges ou d'universités sur cinq survivent, alors que dans le secteur à but lucratif, le taux se rapproche de deux sur cinq. Ces chiffres pourraient amener à conclure que l'avenir des fusions parmi les collèges et universités est solide. Toutefois, si l'efficacité économique est le principal objectif des fusions, il devrait logiquement y avoir un point au-delà duquel l'efficacité d'une fusion commence à faiblir. Or, les fusions reposent sur un autre motif, sans lien avec l'efficacité économique. Elles peuvent en effet engendrer une diversité plus grande des programmes et services, aussi bien parmi chaque établissement collégial et universitaire que dans les systèmes d'enseignement postsecondaires. Si la diversification est le principal but d'une fusion, l'avenir peut se présenter différemment et dépendre de nouvelles méthodes pour trouver des pairs et des partenaires. Cet article analyse les attentes que provoquent les fusions, la mesure dans laquelle ces attentes sont réalistes et les moyens utilisés pour trouver et choisir des partenaires à une fusion. En conclusion, l'auteur suggère que l'efficacité peut faire place à la diversification en tant que principal incitatif de fusionnement, et qu'avant de choisir entre efficacité et fusion et de s'engager à s'amalgamer, les établissements et les systèmes d'enseignement postsecondaires pourraient mettre à l'essai d'autres possibilités de coopération.

\section{WHAT DO WE WANT MERGERS TO DO?}

Since the mid-1980s the principal interest in merger in higher education has been financial. In this respect, the differences between the corporate sector and the educational sector, and between the public 
non-profit sector and the private for-profit sector have not been fundamentally different. Merger is seen as a means of promoting efficiency in production and ensuring an optimal allocation of scarce resources. In other words, mergers allow the reduction of inputs without reducing the level of output. Many mergers have met those expectations. Others have not.

Some mergers fail because the concept of efficiency through economy of scale is poorly understood. Others fail for the same reason that some marriages fail: the partners were incompatible and could not be reconciled. Some mergers that are essentially corporate take-overs fail because they were never intended to succeed; their objective was to eliminate competition and strengthen the dominant partner in the merger.

Diversity can be defined in many different ways (Birnbaum 1983). It can be about institutional form. It can be about equity when it addresses the composition of student populations and of faculty complements. It can be about the availability of programs, the quality of programs, and the ways and means by which programs are delivered. The list could be longer. For example, in South Africa mergers are said to be "transitional" to indicate their role in social, political, and economic integration after the eradication of apartheid (Jansen 2002). In this case merger is not only a form of diversity; it is also a means of creating broader diversity. Diversity, as it relates to merger, is usually about institutional forms, arrays of programs offered, and response to student demand.

This duality of purpose between efficiency and diversity poses several problems. The first is that when one asks about the future of merger, its success or failure, the answers can be different depending on the expectations that were held for merger in the first place. The second is that inherently one purpose of merger - efficiency and productivity can offset the other - innovation and diversity - by discouraging competition. Another problem involves the level of diversity at which merger plays a role. These levels can be described as across and within diversities (Cowen, 2002). Let's say that within a system of higher education there are, among several institutions, two institutions each with different specializations or strengths. When those two institutions merge, the new institution that is created will be more diverse internally or within itself because it will have drawn on the special programs or 
strengths of the two founding institutions. But across the system there will be less diversity because two of its constituent institutions have become one and, more significantly, have become more alike one another. This explains the third problem: is the purpose of some mergers to change the shape or diversity of overall systems of higher education or is it to change only the two partners in merger? These are distinctions that, so far, research about merger has not thoroughly examined.

\section{MONEY TALKS: THE POLITICAL ECONOMY OF MERGER}

More often than not finance motivates mergers and defines what they can achieve (Millett, 1976). The value of a merger (and of most other forms of cooperation or partnership between postsecondary institutions) in the first and often only instance is basically practical and in many cases measurable, in expectations if not in outcome. One observer explained the value this way:

[Institutional] cooperation is one of those concepts, which like a teaspoon or an umbrella, but unlike an earthquake or a buttercup, are definable primarily by the use or purpose which they serve. Although there are persons for whom cooperation seems to have inherent values as a desirable way of life, institutional cooperation has merit only as it contributes to the purposes of the institutions involved - if it makes them more efficient. (Stewart, 1961)

More recent studies have confirmed the findings that finance drives many mergers in higher education (Eastman \& Lang, 2001; Geodegebuure, 1992). Even when financial concerns do not motivate merger, they may still be important ingredients in the success or failure of mergers.

Although the financial motivations for merger differ from case to case, certain patterns are discernible. Moreover and equally important, the motivations often can just as readily explain the formation of a consortium or a federation or some other form of inter-institutional cooperation as a merger. Further, in the case of public institutions, these motives are often shared with governments, many of which actively promote or at least smooth the way for mergers and cooperation. What are some of these motives? 


\section{Looking Up and Looking Down: The Perspective of Scale}

There is an intuitive and sometimes demonstrable view that mergers can realize economies of scale (Brinkman \& Leslie, 1986; Sears 1983). A corollary of that view is that size matters, and that at some level of scale, as in the old saying about marriage, two can live as cheaply as one. It should not be surprising, however, that institutions of different sizes view merger differently, although they both may be attracted to merger in order to reduce or minimize costs by capturing economies of scale (Lang, 2002).

Looking upward towards larger partners, smaller and more specialized institutions perceive merger as offering several opportunities:

- Truly new revenue may be generated from new programs that could only be offered through merger.

- They want to secure net new resources for their programs and services. More often than not, the net gain is due to reduced unit costs than to additional revenue. Thus the "new" revenue is only notional; the real source of financial gain is reallocated saving.

- They want to benefit financially from government incentives to merge with larger institutions.

- Depending on the larger institution's reasons for considering merger, the larger institution may be prepared to direct additional resources to the smaller institution. Those resources usually will be budgetary allocations but in some case they may involve access to better facilities and services than the smaller institution could have afforded itself.

- In "tiered" jurisdictions, merger may relocate the smaller institution to a more favourable location in a funding formula.

- They want to be less lop-sided in terms of program costs.

- They want to achieve critical mass in small areas of specialization.

- Their accumulated debt may assumed by their partner in merger or by the government. 
Some of these reasons could, of course, apply to any merger, but they apply more often to smaller more specialized institutions. In some cases in which merger is promoted or required by government, merger as a matter of public policy has been directed expressly at institutions below a specified size. This was the case in The Netherlands (Goedegebuure, 1992) and in Australia, although in Australia institutional size was expressed in ranges of funding units (Dawkins 1988; Ramsey, 1989).

Intuition also suggests that the larger partner in a merger will be motivated less than the smaller partner by financial considerations. In many cases this intuition coincides with reality, but not always. First, "large" and "small" are relative terms. While a college with 2,000 students will appear small in comparison to a university with 5,000 students, the difference in size between them might not be sufficiently significant to alter their unit costs of instruction were they to merge. There is evidence that significant economies of scale do not begin until enrolment reaches about 9,000 and begin to diminish after about 20,000. So, economy of scale is significant within a range of approximately 9,000 to 20,000 . Outside that range, it makes little difference (Layard 1974; Patterson, 1999; Schumacher, 1983; Toutkoushian, 1999). Thus the college with 2,000 students and the university with 5,000 students are both "small" in terms of economy of scale, and, for that reason, a merger between them would not produce much saving.

Further to the point, the college with 2,000 students might have five different faculties while the university with 5,000 students might have only two. In that case the smaller institution is the more complex. Complexity may drive costs more than absolute size (National Commission on the Cost of Higher Education, 1998), as it often does in for-profit firms (Lawler \& Mohrman, 1996). This conflation of size and complexity can result in diversity posing as efficiency.

Second, economy of scale is not infinite. There is a point at which size no longer confers financial advantage, and beyond which size can be a financial liability (Blau, 1994; Patterson, 1999). Nevertheless, larger institutions in mergers share some objectives with their smaller partners: 
- They may wish to benefit from government incentives that encourage merger. Some government merger schemes offer more to larger "host" institutions.

- They may have small, highly specialized programs that, on their own, are as uneconomic as those in smaller institutions.

- They may gain additional revenue from new programs that merger either makes possible at a lower marginal cost than the larger institution could realize on its own.

- Because of the presumption of economy of scale, larger institutions assume that they can offer the programs of the smaller institution at lower cost, thus producing savings for reallocation. This is also the reason for governments' extending stronger incentives to merge to larger institutions.

- They may gain access to highly specialized facilities, some of which might be underutilized.

\section{What Do Governments Want Mergers To Do?}

Formally and legally mergers are among institutions, but in the case of publicly funded colleges and universities government almost always plays a role in merger. Sometimes the government's role is extremely proactive as when a government forces merger. Many mergers among public colleges and universities are involuntary; they are the creations of government and often have the characteristics of corporate takeovers and acquisitions. In some cases government may force merger but not determine who the partners should be. In other cases, government may establish strong incentives to merge. Those incentives may be positive - financial inducements are offered — or they may be negative as when financial penalties are imposed on institutions that choose to remain independent. Finally, a government may stimulate merger by signaling that it would approve a merger on certain terms, or by indicating that an institution in financial stress will not be rescued by special government intervention.

For mergers among public colleges and universities, then, it is not logically or practically possible to set the objectives of government 
aside. Often governments want the same things that the institutions large or small - want:

- Governments want new programs and a relatively low marginal cost instead of at an average cost. Here governments are victims of their own funding formulas that inherently fund at the average. Merger can make the marginal costs of new programs lower.

- Merger can especially reduce the capital costs of new programs as the sunk costs of previous investments can be more efficiently utilized.

- Governments are driven towards economies of scale just as individual institutions are, and perhaps more so.

There are some objectives, however, that are of greater interest to government than to public colleges and universities. These objectives are not necessarily antithetical to the interests of the institutions, but they may be of less value to them.

- Systems of higher education, particularly in older jurisdictions, may not be rational or efficient in terms of pubic policy because, in the first instance, there may have been no public policy when some of the institutions that make up the system were founded. Or public policy may have changed; an example is the shift to mass higher education with very high rates of participation.

- Demand may have shifted to the extent that certain institutions - typically in under-populated areas - that were viable under conventional funding formulas cease to be viable. Merger in these cases may be a more attractive alternative than receivership or anomalous funding.

- While affordability is of concern at both the institutional level and the government level, the government perspective is different. In most jurisdictions governments fund colleges and universities by block transfer grants; that is, with a few exceptions, they do not specify how an institution should spend the public funding that is made available to it. This causes governments, when faced with affordability problems, to tend to 
think in terms of simple unit costs like funding per student. Their own funding formulas draw them to such a perspective, draw them to thinking of merger as a way of moving all institutions to an average unit cost. This may happen in either direction; college to university or university to college.

- On self-reflection, some governments recognize that they may not have sufficient time or sapience to make sound decisions about all of the public colleges and universities for which they are responsible, particularly smaller and more specialized institutions. Merger seen from this perspective is an organizational device for delegating or narrowing some responsibility to a lower level, specifically to larger institutions that become hosts through merger to smaller, more specialized institutions. (Ontario Ministry of Agriculture, Food and Rural Affairs 1996; van Ravens, 1995)

\section{MERGERS AND DIVERSITY}

Although less frequently cited than economic and financial objectives, we also often want mergers to create diversity where it otherwise might not be possible. The merger of two absolutely identical institutions would be so pointless as to be an oxymoron. Of course, the random or arbitrary merger of different institutions might be equally pointless.

To return to some of the objectives that colleges, universities, and governments hold for merger as a means of reducing and minimizing costs it can be seen that diversity is embedded in some of them. For example, when governments are concerned about their ability to make sound decisions about the management of smaller and more specialized institutions, they are inherently concerned about diversity, because it is diversity that makes those institutions expensive to manage.

Larger institutions naturally tend towards diversity and comprehensiveness, and therefore often regard a merger as a form of corporate take-over. As they do, they become concerned about balance and filling programmatic voids. Merger is a means of filling a void at lower cost, especially capital cost. This explains why in a merger a larger institution may be willing to assume the debt of a smaller institution. In practical 
terms, the larger institution would be buying additional programs for the cost of their debt. In certain cases that could be a bargain. Here again, the objective is in the first instance diversity. Merger is an efficient and economic means towards the end of diversity.

Governments sometimes want new programs in response to expanding demands for accessibility. But they sometimes want those programs in order to expand diversity, either for competitive reasons or for reasons of public policy. An example of the first expansion of diversity is the addition of programs in areas that enhance global economic competitiveness, as in the case of the merger in Canada of the Technical University of Nova Scotia and Dalhousie University. Examples of the latter are the array of "transitional" mergers imposed by government on South African colleges and universities, and the "upgrading" that characterized some of the mergers in Australia and Canada as sub-baccalaureate programs in Nursing were merged into universities.

So, a second but not necessarily subordinate expectation of mergers is to produce diversity. This is easier said than done, particularly in contrast to the expectations about economy and efficiency. Mergers of institutions with complementary missions and strengths are more successful than mergers of institutions that are fundamentally different from one another (Eastman \& Lang, 2001). This means two things. First, the role that mergers can play in promoting diversity needs to be clarified and separated from the role that they play in promoting economy and efficiency. The roles are not only different; they are often mutually exclusive and conscious choices have to be made about which objective should have priority. For example, if the optimal size of universities in terms of cost is slightly greater than 20,000 (Patterson, 1999; Toutkoushian, 1999) many systems of higher education should have a few large institutions and no small or middle-size institutions, which in turn would mean less diversity.

This is a choice that governments, when they become involved in merger, often overlook or avoid. Second, more must be known about the influences that engender diversity. How does one recognize and plan for diversity? Mergers for which the objective is greater diversity must be carefully planned, especially in terms of identifying institutions that will 
make good partners in merger. The track record of mergers in the public sector - not only the higher educational sector -indicates that their success rate depends on the rationale by which institutions are selected as partners in merger. "Mix and match" may work in the fashion industry but it doesn't work for mergers.

\section{Diversity: What Is It and From Where Does It Come?}

Diversity is a policy objective that most systems of higher education pursue, either collectively or institution by institution. The natural inclination of individual colleges and universities is to become more diverse, usually by adding programs. There are several different concepts of diversity and of what causes it. Robert Birnbaum (1983), who has written extensively about diversity in higher education, for example, identified at least six different kinds of diversity and two different paradigms — "natural selection" and "resource dependence." He and others further observed that none of the conventional, broadly applied classification schemes for identifying diversity satisfactorily accounts for all institutional characteristics (Birnbaum, 1983; Huisman, 1998).

There are other paradigms. In terms of typologies of institutions and the degrees of diversity that they represent, the paradigm of natural selection is very powerful. Natural selection is essentially the application of a Darwinian model of an ecological system to institutions of higher education, or more exactly to groups of institutions just as there are multiple organisms in an ecosystem. How does the natural selection model explain inter-institutional cooperation through merger? Merger may be a means, perhaps the only means, of institutional survival. Like any species in an ecosystem, colleges and universities will seek to survive, and will choose change over the status quo in order to do so. The complexity of ecosystems, perhaps like systems of postsecondary education, can, on the one hand, be so great as to be less than comprehensible while, on the other hand, reflect the essential role that specialization and diversity play in maintaining the health of the system. Seen from this perspective, any system of higher education contains a plethora of unique niches that are constantly changing. Merger in this sense can be regarded as the institutional equivalent of genetic variability. Each 
merger represents a unique combination of institutional characteristics that together move the participating institutions to fill a new niche by evolution.

But as in an ecological system not all species survive. Some fail to evolve and die. Some evolve but disappear into merger. Moreover, not all that survive do so by symbiosis. Some evolve without cooperation with others. But in those cases that do involve formal cooperation, either in the biological sense or the organizational sense, the success of merger depends on the compatibility of the two institutions. Success in a merger does not occur randomly. Some institutions make a good fit together while others do not.

Yet another paradigm is resource dependence. Resource dependence is, at least superficially, similar to the paradigm of natural selection: the fundamental objective of the organization is to survive. The resource dependence paradigm ties survival, however, to a single factor: resources or money (Birnbaum, 1983; Goedegebuure, 1992). That factor includes as well the authority or franchise to raise or claim money (Goedegebuure, 1992). It should not be surprising then that in the case of public colleges and universities the role and posture of government is paramount because government is the source of the majority of funding on which the institutions depend. In these cases, the difference between voluntary and involuntary merger might be moot.

Nor should it be surprising that merger seen from the perspective of the resource dependence borrows from the idiom of monopolies. For example, a merger that involves institutions that operate in a similar field and offer similar programs (or "products") might be described as "horizontal" while a merger that involves institutions in a similar field but which offer different products might be described as "vertical" (Steiner, 1975). The analogy to economic monopolies of course is not perfect. But that is not the point. The point is that the motivation to form monopolies through merger is to secure and control resources, and, once they are secured, to protect them from competition. Protection from competition may enhance the security of resources but may also discourage diversity and innovation.

Joseph Ben-David (1972) argued that diversity is the product of competition, and that competition is greatest when colleges and universities 
are relatively independent. Roger Geiger (1986) came to a similar conclusion in his study of the differences between public and private sectors in higher education. This would imply, further, a paradigm rooted in organizational behaviour and system structure. Moreover, the implication is a paradigm inhospitable to voluntary merger.

So, while the competition paradigm and the resource dependence paradigm share a common ground in the marketplace, they explain the phenomenon of merger quite differently. One depends on the marketplace to determine how institutions change and adapt through merger while the other seeks by merger to insulate institutions from the marketplace, and in particular from the possible loss of resources to the marketplace.

The final paradigm that explains institutional diversity might not be a paradigm at all, but it is important, particularly in juxtaposition with the other paradigms, especially as they relate to involuntary mergers. A conundrum that confronts several of the other paradigms that attempt to explain institutional differentiation and varying postures towards merger is that the shape and composition of the political jurisdictions in which postsecondary educational systems function are not themselves the product of, for example, natural selection or competition. History, culture, language, and geography are far more frequent determinants of political jurisdictions. Any one of these factors can explain certain circumstances that might lead to merger or discourage it. This paradigm may explain, for example, the path taken by South African colleges and universities towards merger. Patterns and forms of merger under this paradigm are to a very large extent determined by government policy, and are virtually synonymous with reorganization and restructuring by government fiat (Jansen 2002).

\section{The Use of Peer Selection Methodologies: Finding Partners for Merger}

Peer selection, as a policy issue, began to grow in importance as interest in accountability and performance indicators grew, and as colleges and universities came under greater pressure to perform efficiently, which is also an objective of merger. It is therefore also inherently important to merger as a means of determining which combinations of institutions would produce the greatest efficiency or diversity, or both. 
In order to make informed decisions about strategy and resource allocations individual institutions might quite legitimately wish to construct comparisons with other institutions for the purposes of benchmarking. Benchmarking is not necessarily about performance or accountability. It can also be a means of identifying the differences and similarities that make successful mergers possible. It is important to understand that a methodology by which peers are selected is also a methodology for identifying institutions that are not peers, and, more specifically, for indicating the area in which they are unalike. So, when one talks about peer selection in the context of merger the implication is not that peers necessarily make good partners in merger.

Comparisons made ad hoc, either because data are readily available or because comparisons with certain other institutions produce intuitively desirable results, are inherently unreliable and cannot serve accountability and management well. The same can be said about mergers: partners should not be selected only because they are willing, available, and geographically nearby. "Because they are there" might be a plausible reason to climb mountains, but it is a very bad reason to select partners for merger. Convenience and politically useful results should not form the basis of peer selection or the selection of partners for merger Yet, in the absence of systematic means of determining peers and partners for merger, that is an entirely possible and unfortunately misleading result.

\section{Peer Selection and Diversity: Where Do They Intersect For Mergers?}

Peer selection is as much an art as a science. The ultimate objective of any methodology for determining peers for comparison should be to ensure that the institutions are sufficiently similar for comparisons to make sense, or are sufficiently dis-similar and complementary for merger to make sense. Institutions have different roles, some deliberately set as mission statements while other roles are the products of history; others still are the unfortunate consequence of institutional drift. Institutions are different in terms of size and location. They are different in terms of organizational complexity, which is not necessarily determined by size. They may be different in terms of cost structures. They are different in terms of programs and of markets for those programs. They are different in terms of quality. 
In the first instance these are factors that a college or university should take into account in deciding whether or not to consider merger. For example, if it appears through reliable comparison that the problems facing a particular institution are endemic, or that a given institution is performing as well as other institutions, the benefits of merger might be quite limited.

Assuming in the second instance that merger does appear to hold possibility for the given institution, all of these are factors that the college or university should take into account in appraising possible partners for merger. The practical question that follows is about the ways and means of making such an appraisal reliably.

An obvious, although frequently overlooked, matter of fact is that institutions are not systems, and vice versa. Institutions often have certain characteristics because of the systems of which they are a part. Even institutions that are afforded high degrees of autonomy sometimes are defined in certain respects by the public jurisdictions in which they are located. Institutional mergers, then, cannot in all cases occur without reference to system structures and policies even if the institutions involved enjoy high levels of autonomy. If certain conditions apply to all institutions in a system, they will apply to any putatively new institutions that are formed by merger. In other words, it is not possible for a college or university to "merge" its way out of a system.

But if one asks whether or not a given system of higher education is becoming more or less diverse, a logical connection to peer selection and merger emerges. Systems can change, first, in two ways: they can add or remove institutions or the existing institutions in them can change. Institutional change, in turn, can involve three further possibilities. The array of institutions can remain the same while individual institutions become more diverse internally. The number of institutions can grow, with the new institutions introducing the desired diversity. Or institutions can merge or, more likely, be forced by government to merge.

In the absence of absolute standards or frames of reference in higher education for the evaluation of institutional performance, governors and administrators understandably tend to turn to the behaviour of other institutions, either individually or as a group, to establish norms for 
guidance. Management of higher education is plagued by the "How much is enough?" question. There are no convenient algorithms to determine, for examples, what percentage of an institution's budget should be spent on library acquisitions or how much should be budgeted to produce a given number of instructional hours, or indeed how much diversity is optimal.

This is an important question in regard to mergers. One of the more salient reasons for the merger of institutions is to increase diversity, particularly at a lower cost than would be incurred by each institution's acting alone. Increasing diversity in this context might mean, for example, adding academic programs or library collections. This is a reason for governments to support mergers as well as for individual institutions to seek them. Some "how much is enough" inquiries about diversity suggest counter-intuitive results in regard to mergers. On the one hand, for example, if large institutions are more differentiated, and large, complex institutions require greater investments in administration because complexity is more difficult to manage (Berdahl, 2000; Blau, 1994; Callan, 1994), then reducing the cost of administration in the name of efficiency can discourage diversity.

This leads to a great and growing dilemma for the future of merger. Efficiency and economy are among the strongest reasons for merger. So, which performance is more important: administrative efficiency or diversity, and which can be best pursued through merger? This is a dilemma because of the inverse relationship between the costs of diversity and the costs of the management that diversification requires. Merger could have one future or the other but usually not both.

There are a number of quite different ways that administrators and policy-makers may attempt to address this question. One of the most straightforward is to examine the degree of diversity that is already being managed by the institutions considering a merger. Is that level of diversity being managed well? If it is, how much spare capacity for managing further diversity will be available after the merger, or is management an area that merger is being undertaken to reduce? 


\section{THE FUTURE OF MERGER WHEN MERGER WONT WORK}

Although the track record of merger contains more successes than failures (Eastman \& Lang, 2001) it is not a record that can commend merger universally. Sometimes merger either does not work or, at least, does not work any better than other forms of cooperation among colleges and universities. If the motivating theme of merger in higher education is more often than not economy and efficiency, the case for merger, even when other educational objectives are involved, finally rests on less costly means of realizing those objectives.

Mergers do not always result in greater diversity. One reason for this has already been discussed: diversification demands intensified and, sometimes, specialized management that poorly matched mergers either cannot deliver or can deliver only at higher administrative cost. Another reason is that some mergers, in terms of the institutional characteristics that normally define diversity, gravitate towards one or the other, but not both, of the institutions that merge. In Lynn Meek's assessment, that is what happens in most mergers between colleges and universities:

In [U.K.] university/college mergers, the outcome of merger is always a university. Since the university is usually the most powerful partner in a merger, the success of a university/college merger largely depends on the attitudes adopted by university personnel. Warwick, Exeter and Loughborough have produced successful mergers because university leaders believed in the potential benefits of the merger and saw that the acquisition of a college would give them the opportunity to pursue activities otherwise closed to the university (Meek, 1988).

The mergers of which Meek spoke would be regarded as successful in the sense that the merged institutions are still in place, and are financially viable, often because of the efficiencies that merger made possible. But the consequence of mergers that take this course is less diversity. This may be the case in some of the mergers that were mandated by government in South Africa (Jansen, 2002).

So, if it is accepted that efficiency and diversity are the two principal factors that motivate merger, it should not be surprising that the move towards merger is slowing in some jurisdictions (Martin \& Samels, 2002). 
What, then, are some of the areas in which merger is less effective, and what are the alternatives for those areas?

\section{When Institutional Cultures Conflict}

There is sometimes a tendency to take a romantic view of mergers - to regard them as "marriages of equals"" that bring forward the "best of both" and allow "two to live as cheaply as one." That is one possible outcome of merger, provided that there are high levels of commonality of purpose, mutual understanding and good will between the parties and sustained and effective communication throughout the process. Just as often, however, mergers give rise to confusion and conflict (Martin \& Samels, 2002; Soobrayan, 2002). Precisely because no party dominates, issues may proliferate, fester and remain unresolved. Depending on the cost structures and markets of the merging institutions, two might not be able to live as cheaply as one, and the costs of management may rise as the new institution is more complex but not necessarily cheaper to run.

A study of the financial services industry by the American Bankers Association and Ernst \& Whinney found that cultural blending strategies associated with mergers of putative equals often precipitated severe conflict between merger partners. Buono and Bowditch illustrated what can happen with reference to the case of two law firms.

[T] he two firms initially appeared initially to be a model for law-firm combinations. The union was friendly, a managing partner was assigned as a mediator to help resolve internal disputes and each firm's partners admitted that the time had come to 'inculcate some new values.' Within a year after the merger, however, instead of 'blending together,' post-combination interactions were described as tension laden and confrontational. As a result, the billing system broke down, the managing partner who was supposed to resolve internal disputes quit, a number of other partners left the firm, taking millions of dollars' worth of clients with them, and long-term clients began using other law firms. Ironically, it seems that many of the problems were related to the cultural blending strategy: since neither firm emerged as dominant after the merger, virtually everything from pay scales and whose clerks and secretaries would be dis- 
missed to which associates would be asked to leave - had to be negotiated. Instead of exchanging values and selecting the best features of each firm, the process broke down as the cultures repeatedly clashed with each other. (Buono \& Bowditch, 1989)

One alternative to the conflict of cultures may be along the lines of Meek's observation about the success of mergers in the U.K.: allow one culture to dominate. Another alternative, which was deployed in some mergers in Canada, is to allow the smaller or less predominant institution a degree of internal autonomy, either through modifications in governance or through some version of "flow through" Responsibility Centre Budgeting (Eastman \& Lang, 2001). If governments are indirectly parties to merger they can protect the minority partners by providing earmarked funding as if the partners were still autonomous This results in a degree of semi-autonomy. For example, when the Osgoode Hall School of Law merged with York University in Ontario, the government continued to provide such grants. Also in Ontario, the affiliated campuses of Laurentian University, a small institution in the province's relatively unpopulated north, receive separate earmarked funding but are academically accountable to their host university.

But sometimes none of those alternatives works. In public systems of postsecondary education, an alternative to merger can at the same time be simpler and more radical: close an institution or, more probable, close a program and reassign responsibility to another institution. A plausible case can be made that a number of mergers in The Netherlands and Australia were of this ilk (Goedegebuure, 1992; Harman, 1989). In both jurisdictions the government's official position was that institutions of a certain scale or less were not forced to merge, but if they did not, their funding would be withdrawn or cut-back. (Dawkins, 1987; Deetman, 1983).

This alternative does not imply that the future of merger is bleak. What it implies is twofold. First, the form of merger may in the future tend towards take-overs and acquisitions as those terms are already understood in the for-profit corporate sector. Second, in the case of mergers among public colleges and universities, especially mergers that are promoted or mandated by government, some a priori action by government might be required to define the course that mergers should take. For example, two 
institutions may be called on to merge but only after government determines that, in the course of merger, some programs will be discontinued or transferred to other institutions. In Ontario, in the early days of discussions about what in the end was the merger of the University of Toronto and the Ontario Institute for Studies in Education, the provincial government considered just such a plan (Eastman \& Lang, 2001).

\section{When Economy of Scale is Misunderstood}

Economy of scale, which is the basic concept behind the efficiency of merger, is not infinite. There is a certain generic logic to this. In higher education, economy of scale favours larger institutions. There is, both in theory and in practice, an upper limit to the inverse correlation between institutional size and unit costs but the available evidence indicates that this upper limit is very high (Schumacher, 1983). The most recent studies of the correlation between institutional size and unit costs indicate that beyond enrolments of about 20,000, increases in size do not lead to greater efficiency (Patterson 1999; Toutkoushian 1999). Thus there is little history of mergers among very large institutions, although some large institutions participate in consortia and federations. Indeed, some of the world's largest universities are federations, for examples, the University of London and the University of Toronto.

A graphic representation of economy of scale is a reversed letter $\mathbf{J}$. Unit costs decline along the longer upward leg of the $J$ as volume expands, thus approaching the bottom or curved portion of the backward J. However, as volume expands further, unit costs begin to rise again, along the shorter upward curve of the reversed J. Merger, as a means of realizing efficiency, works until the expansion of volume begins to drive unit costs up again. After that the marginal value of merger begins to decline. This portends several possibilities for the future of merger.

The first is obvious: to the extent that a search for reduced costs drives institutions and governments towards merger, there will be less interest in merger. The second is that mergers aimed at efficiency and economy may shift to emphasize the maximization of revenue through merger. An example from Canada is that as programs in Nursing have moved from community colleges to universities through merger (another 
term for this in Canada is "articulation") tuition fees have risen to the university level.

Third: diversification will become the dominant purpose of merger. If diversification becomes the dominant purpose for merger, merger might become less popular because there are other forms of inter-institutional cooperation that can produce as much diversity as mergers, but without the irrevocable finality and loss of identity that accompany merger (Lang, 2002).

There might be a fourth but much less obvious future. Just as there is an optimal size of institution in terms of economies of scale, there may be an optimal scale of formal systems of higher education. There are some voices that argue that public systems of higher education are becoming too big, too highly centralized, and too complex to be managed successfully by anyone (Berdahl, 2000; Callan, 1994; Gaither, 1999; Mac Taggart, 1996). Recalling that merger occupies a place on a continuum with other forms of inter-institutional combination (Lang, 2002), one might expect merger to evolve towards the end of the continuum where highly organized systems are located. Those systems might be reduced in scale and complexity through mergers that form smaller, more specialized "mini-systems" that are more homogeneous than heterogeneous.

Finally, if economy of scale as it applies to mergers is better understood, the expectations for merger may change with the result that interest in other forms of inter-institutional combination may grow. There is an assumption, often made but infrequently acknowledged, that the principle of economy of scale is not only infinite but applies to all costs. It doesn't. Libraries, information systems, fund raising and development, building operation, maintenance, and depreciation are examples of major cost centres that are largely fixed. These costs are not reduced in merger. They are simply added together in the budget of the merged institution. The significance of this is that whatever percentage of saving economy of scale might produce in a merger applies only to a subset of costs, perhaps as little as 50 to $60 \%$ of total cost.

With that lesson learned, colleges, universities, and governments that contemplate merger might look to other forms of partnership, like consortia, that can focus on specific areas in which the principle of economy of scale does apply. 


\section{CONCLUSION: THE EFFICIENCY — DIVERSITY TRADE-OFF}

Diversity is neither infinitely valuable, nor affordable, nor manageable: there can be too much diversity just as there can be too little. This poses problems for at least three critical areas of public policy towards higher education: planning, regulation, and funding. It also poses problems for institutions that are considering merger and for public systems that are seeking greater diversity and rationalization by promoting mergers. It is at this point that diversity begins to share some characteristics with the ways and means by which colleges and universities identify their peers and, in the case of voluntary mergers, their partners for merger. In the case of involuntary mergers, these ways and means inform governments about the shape and diversity of systems of postsecondary education that they deploy merger to create. So, what mergers do is often the result of how institutions are selected for merger.

If that selection is done well, there can be two beneficial results. The first is that efficiency and diversity may not have to be traded-off against one another. Diversity may produce efficiency as the marginal costs of expanding programs and services are minimized through merger. Efficiency may make more diversity possible.

The second beneficial result is that more mergers will be stable and long-lasting. Those characteristics are more important for diversity than for efficiency for most publicly funded colleges and universities. Mergers for efficiency often have a "the Devil made me do it" dimension. Mergers for diversification are more fundamental and require greater acceptance at the grassroots of colleges and universities. Thus, while diversification mergers may be more complex and difficult to implement, they are also more likely to produce permanent results.

There is a big if: "IF the selection is done well." One reason for the emphasis here on diversity and the use of peer selection methodologies to select institutions for benchmarking and merger is that so far this has not always been done well or, in some cases of government mandated mergers, done at all. There are methods for making these selections (Lang, 2000) The future of merger, especially the future that aims to balance efficiency and diversity, may include greater attention to those methods. 
Forecasting the future of mergers in higher education depends to a considerable degree on two inter-related factors. One comprises the reasons for the interest in merger in the first place, most of which arose in the last three decades of the 20th century. The other comprises one's understanding of where merger fits among all of the forms that interinstitutional cooperation may take. While merger may be the predominant form that the recent expansion of inter-institutional combination has taken, it is not a unique or independent form. It shares a number of fundamental characteristics with other forms of cooperation, especially federation, and evolved from those forms.

In virtually any case, one should expect the future of merger to have an outer, finite limit. There is a point at which the returns from efficiency will begin to diminish as institutional scale reaches optimal levels. This suggests, first, that the prospect of merger will remain significant for smaller and more specialized institutions. Second, it suggests that the small, specialized colleges and universities that decide to pursue merger will be more likely to seek larger, more comprehensive partners than to seek partners among institutions like themselves. The reverse is also likely to be the case: in the future larger institutions that consider merger will be more interested in gaining curricular specialization and variety than in realizing economies of scale. If those three trends are true, the alternatives to merger, especially affiliation and federation, may become more attractive than merger. Thus the future might hold more inter-institutional cooperation but less merger.

In forcing merger as part of such rationalization, governments have often assumed that merger will lead to greater efficiency and productivity. Whether or not governments have known enough about costs and institutional management to make such an assumption reliably, it too is a principle that, like economy of scale, produces fewer returns as systems become more rationalized through merger, voluntary or involuntary. Given the already great extent of mergers that were either required or motivated by the reorganization of systems of higher education, there may simply be little room left for more mergers.

Governments and institutions may be gaining in their understanding of what mergers can and cannot deliver. The conclusion to be drawn from 
this observation is that there might be fewer new mergers in the future but their success rates will rise as expectations become more realistic.

Will anything follow merger as a new form of inter-institutional combination? First, merger may evolve to the formation of "mini" systems of higher education. There is some evidence of this phenomenon already. Several of the mergers in the Netherlands and Australia involved as many as a dozen institutions. These were sometimes described as "conglomerate mergers" (Goedegebuure, 1992). On careful examination, however, some of these newly merged universities look more like small systems of higher education than like separate and individual institutions. Some of them, particularly in Australia, have remained geographically dispersed, spreading literally over hundreds of kilometers. They are often highly diverse and regional (Harman, 1991). They have the characteristics of what some large centralized systems of higher education call "segments." They also resemble and behave like some large federations or what might be described as "near mergers."

Given some of the problems that mergers have encountered in governance and internal decision-making.(Martin \& Samels, 2002) the future of mergers may include more deployment of financial arrangements like Responsibility Centre Budgeting (Lang, 1999) and other "flow through" schemes like management by contract (Lang, 2002).

Finally, involuntary merger forced and planned by government may come to be seen as something other than merger, especially if priority shifts from simple cost reduction efficiency to diversity. Efficiency is a motivating influence towards merger for both individual institutions public or private - and governments. Although they may measure efficiency differently and seek other means of achieving it, institutions and governments both may be drawn to merger because of it. Diversity and the institutional forces that lead to it are a different matter. Although governments often want diversity, and often seek to get it by requiring or inducing mergers, in the end colleges and universities are as inclined to compete as to cooperate when expanding programs and thus adding to aggregate diversity. The result ineluctably is merger by political force majeure. In that case and in generic terms, what happens is a restructuring or rationalization of a public system of higher education by govern- 
ment. This is not merger. It is a new way of balancing efficiency and diversity. An apposite example can be drawn from the procurement underway now of a new jet fighter aircraft by the United States and several other governments, including Canada, in cooperation. The basic idea is that a family or "platform" of closely related airplanes can, on the one hand, be different enough to meet the various needs of the participating military services and, on the other hand, similar enough to capture significant economies of scale. When applied to higher education, this idea of a "family" of services that are similar enough to reduce costs through economies of scale is very much like those systems of colleges and universities that are being restructured under the outward appearance of a series of individual mergers. But merger isn't really the point or the purpose. Instead the point seems to combine efficiency and diversity by centralizing "backroom" utility functions to realize economies of scale, while leaving academic programs largely intact within a sort of higher educational holding company that is some degree short of true merger.

This "near merger" has more characteristics of a consortium or a federation than of a merger. The lesson for the future might not be that mergers can fail, but that even a successful merger may do too much. Instead of expanding diversity, some mergers may only trade one kind of diversity for another. Future mergers undertaken in the name of efficiency may, first, have large transaction costs that will consume savings for several years, and, second, produce savings that are either below expectations or no greater than the savings that other, less inclusive, forms of partnership could have produced.

Mergers often force a trade-off between efficiency and diversity. Because they are total and only rarely reversible (Harman \& RobertsonCuninghame, 1995), if a merger does not work, it will be difficult if not impossible for either partner to return to the status quo ante. In the future colleges, universities, and systems that are seeking greater efficiency or more diversity might avoid the trade-off by not thinking of merger first. Instead the evolving pattern might be a gradual and cautious creep in the direction of merger, with some stops along the way at other forms of inter-institutional combination. 


\section{References}

Ben-David, J. (1972). American Higher Education. New York, NY: McGraw-Hill.

Berdahl, R. (2000). A view from the bridge: Higher education at the macromanagement level. The Review of Higher Education, 24(1).

Birnbaum, R. (1983). Maintaining diversity in higher education. San Francisco, CA: Jossey-Bass.

Brinkman, P.T., \& Leslie, L. (1986). Economics of scale in higher education: Sixty years of research. Review of Higher Education, I(1).

Blau, P. (1994). The organization of academic work, 2nd Edition. New Brunswick, NJ: Transactions.

Buono, A., \& Bowditch J. (1989). The human side of mergers. San Francisco, CA: Jossey Bass.

Callan, P. (1994). The gauntlet for multicampus systems. Trusteeship, May-June.

Cowen, T. (2002). The fate of culture. The Wilson Quarterly, 25(4).

Dawkins, J. (1987). Higher education: A policy discussion paper. Canberra: Australian Government Publishing Service.

Dawkins, J. (1988). Higher education: A policy statement. Canberra: Australian Government Publishing Service.

Deetman, W. (1983). Scale-enlargement, task-reallocation, and concentration. Gravenhage: SDU.

Eastman, J., \& Lang, D. (2001). Mergers in higher rducation: Lessons from theory and experience. Toronto, ON: University of Toronto Press.

Gaither, G. (1999). The multi-campus system: Perspectives on practice and prospects. Sterling, VA: Stylus.

Geiger, R. (1986). Private sectors in higher education. Ann Arbor, MI: University of Michigan.

Goedegebuure, L.C.J. (1992). Mergers in higher education. Utrecht: Center for Higher Education Policy Studies.

Harman, G. (1991). Institutional amalgamations and abolition of the binary system in Australia under John Dawkins. Higher Education Quarterly, 45(2).

Harman, G. (1989). The Dawkins reconstruction of Australian higher education. Higher Education Policy, 2(2).

Harman, G., \& Robertson-Cuninghame, R. (1995). The Network UNE Experience. Armidale, NSW: University of New England. 
Huisman, J. (1998). Differentiation and diversity in higher education. In J.C. Smart (Ed.), Higher education: Handbook of theory and research, Vol. XIII. New York, NY:Agathon.

Jansen, J. (2002). Mergers in higher education: Theorising change in transitional contexts. In J. Jansen (Ed), Mergers in higher education: Lessons learned in transitional contexts. Pretoria: University of South Africa.

Lang, D. (1999). Responsibility centre budgeting and responsibility centre management in theory and practice. Higher Education Management, $1 /(3)$.

Lang, D. (2000). Similarities and differences: Measuring diversity and selecting peers in higher education. Higher Education, 39(1).

Lang, D. (2002). A lexicon of inter-institutional cooperation. Higher Education, 42(1).

Lawler, E., \& Mohrman, S. (1996). Organizing for effectiveness: Lessons from business. In W.F. Massy (Ed.), Resource allocation in higher education. Ann Arbor, MI: The University of Michigan Press.

Layard, R. (1974). The cost-effectiveness of the new media in higher education. In K.G. Lumsden (Ed.), Efficiency in universities: The La Paz Papers. Amsterdam: Elsevier.

MacTaggart, T. (1996). Restructuring higher education. San Francisco, CA: Jossey-Bass.

Martin, J., \& Samels J.E. (2002). We were wrong: Try partnerships, not mergers. The Chronicle of Higher Education, May, 17.

Meek, L. (1988). Notes on higher educational mergers in the United Kingdom. In G. Harman \& L. Meek (Eds.), Institutional amalgamations in higher education. Armidale, NSW:University of New England Press.

Millett, J.D. (1976). Mergers in higher education: An analysis of ten case studies. Washington, DC: American Council on Higher Education.

National Commission on the Cost of Higher Education. (1998). Straight talk about college costs and prices. Washington, DC: Oryx.

Ontario Ministry of Agriculture, Food, and Rural Affairs and The University of Guelph. (1996). Memorandum of Agreement.

Patterson, G. (1999). Findings on economies of scale in higher education: Implications for strategies of merger and alliance. Paper presented at the EAIR 21 st Annual Forum, Lund University, Sweden.

Ramsey, G.A. (1989). Report of the Task Force on Amalgamations in Higher Education. Canberra: Australian Government Printing Service. 
Schumacher, C. (1983). The problem of scale in higher education. In S. Goodlad (Ed.), Economies of scale in higher education. Guildford: Society for Research in Higher Education.

Sears, K. (1983). Economies of scale in higher education. In S. Goodlad (Ed.), Economies of scale in higher education. Guildford: Society for Research in Higher Education.

Soobrayan, V. (2002). The incorporation of the South African College for Teacher Education into the University of South Africa. In J. Jansen (Ed.), Mergers in higher education: Lessons learned in transitional contexts. Pretoria: University of South Africa.

Steiner, P.O. (1975). Mergers: Motives, effects, policies. Ann Arbor, MI: University of Michigan Press.

Stewart, B. (1961). Cooperation by independent colleges: The associated colleges of the midwest. Liberal Education, 47(3).

Toutkoushian, R. (1999). The value of cost functions for policymaking and institutional research. Research in Higher Education, 40(1), February.

van Ravens, J. (1995). The franchise model. Tertiary Education and Management, l(1). 